\title{
Knowledge, Perceptions, and Self-reported Performance of Hand Hygiene Among Registered Nurses at Community-based Hospitals in the Republic of Korea: A Cross-sectional Multi-center Study
}

\author{
Hyang Soon Oh \\ Department of Nursing, College of LIfe Science and Natural Resources, Sunchon National University, Suncheon, Korea
}

Objectives: To assess the nurses' hand hygiene $(\mathrm{HH})$ knowledge, perception, attitude, and self-reported performance in small- and medium-sized hospitals after Middle East Respiratory Syndrome outbreak.

Methods: The structured questionnaire was adapted from the World Health Organization's survey. Data were collected between June 26 and July 14, 2017.

Results: Nurses showed scores on knowledge (17.6 \pm 2.5$)$, perception (69.3 \pm 0.8$)$, self-reported HH performance of non-self (86.0 \pm 11.0), self-reported performance of self (88.2 \pm 11.0$)$, and attitude (50.5 \pm 5.5$)$. HH performance rate of non-self was $Y_{1}=36.678+$ $0.555 X_{1}$ (HH performance rate of self) (adjusted $R^{2}=0.280, p<0.001$ ). The regression model for performance was $Y_{4}=18.302+0.247 X_{41}$ (peception) $+0.232 X_{42}$ (attitude) $+0.875 X_{42}$ (role model); coefficients were significant statistically except attitude, and this model significant statistically (adjusted $\mathrm{R}^{2}=0.191, p<0.001$ ).

Conclusions: Advanced HH education program would be developed and operated continuously. Perception, attitude, role model was found to be a significant predictors of $\mathrm{HH}$ performance of self. So these findings could be used in future $\mathrm{HH}$ promotion strategies for nurses.

Key words: Hand hygiene, Health care-associated infection, Knowledge, Nurse, Perception, Performance

\section{INTRODUCTION}

Health care-associated infections (HAls) critically impact patient outcomes, increase hospital costs, and extend hospital

Received: December 12, 2017 Accepted: April 6, 2018

Corresponding author: Hyang Soon Oh, PhD

Department of Nursing, College of Llfe Science and Natural

Resources, Sunchon National University, 255 Jungang-ro,

Suncheon 57922, Korea

E-mail: ohs2012@nate.com

This is an Open Access article distributed under the terms of the Creative Commons Attribution Non-Commercial License (http://creativecommons.org/licenses/by$\mathrm{nc} / 4.0 / /$ which permits unrestricted non-commercial use, distribution, and reproduction in any medium, provided the original work is properly cited. stays [1]. At any given time, about 1 in 25 inpatients has an HAl. This leads to the loss of tens of thousands of lives and costs the US health care system billions of dollars annually [2]. The primary transmission route of pathogens between patients in HAls is via health care workers (HCWs)' hands [3]. Thus, hand hygiene $(\mathrm{HH})$ is the single most important factor for preventing HAls [1].

Proper $\mathrm{HH}$ among HCWs is one of the foremost techniques for reducing HAls [1,2]. However, the reported rates of $\mathrm{HH}$ performance among HCWs are low, ranging from 18.3 to $68.0 \%$, which is insufficient to satisfactorily prevent HAls $[1,4]$.

During the Middle East Respiratory Syndrome (MERS) outbreak from May 20 to July 28, 2015 in the Republic of Korea 
(hereafter Korea), there were 186 confirmed MERS cases nationwide $[5,6]$. We learned several important lessons from the MERS outbreak, including that $\mathrm{HH}$ is the key to infection control and prevention. Thereafter, various types of educational initiatives, campaigns, and training about $\mathrm{HH}$ have been implemented nationally, ranging from large cities to small-tomedium cities.

In Korea, infection control programs have been developed and implemented at university-affiliated hospitals in large cities, and these programs have spread to hospitals in small-tomedium cities [7]. Studies of $\mathrm{HH}$ performance and knowledge among HCWs have been conducted in larger hospitals with good resources for $\mathrm{HH}$ [8-10]. However, few studies have investigated knowledge and perceptions of $\mathrm{HH}$ among HCWs in small-to-medium hospitals with relatively limited resources.

Because of their frequent contact with patients, nurses' proper execution of $\mathrm{HH}$ plays an especially important role in the prevention of HAls, and nurses should therefore be provided with essential and up-to-date HH information. It has also been established that nurses' knowledge, perceptions, and attitudes about $\mathrm{HH}$ influence their $\mathrm{HH}$ performance [11-13].

As such, this study was conducted to assess the status of knowledge, perceptions, and performance of $\mathrm{HH}$ among nurses in community-based hospitals in a small-to-medium-sized city in an urban region in Korea after the MERS outbreak, to identify the factors that influenced their knowledge, perceptions, and performance, and to identify relationships among their knowledge, perceptions, and performance.

\section{METHODS}

\section{Study Design}

A cross-sectional design was used to administer a self-reported questionnaire, which took approximately 20 minutes to complete.

\section{Settings}

Before the start of the study, the author contacted the hospital directors to explain the purpose of the study and to obtain permission for recruitment. The enrolment criteria were hospitals that were affiliated with teaching hospitals and permitted nurses to participate voluntarily in this study. Finally, 5 community-based hospitals affiliated with teaching hospitals located in a small-to-medium-sized city in the South Jeolla Province of Korea were enrolled in this study.

\section{Participants}

We performed a power analysis using $\mathrm{G}^{*}$ power version 3.1.9.2 (Franz Faul, Universitat Kiel, Germany) to determine that a sample size of 270 would be required to achieve a power of 0.80 with an effect size of 0.15 (a medium effect size for multiple correlations) with an alpha of 0.05 . A convenience sample of registered nurses (RNs) was recruited from the 5 hospital study sites. The hospitals fully understood the purposes of the study and permitted voluntary recruitment; subjects' participation was voluntary and anonymous. Questionnaires were delivered directly to, and later collected from, each hospital. Data were collected from June 26 to July 14 , 2017. A total of 300 questionnaires were distributed and 293 were returned (response rate, 97.7\%). After excluding incomplete questionnaires, 289 questionnaires were used for the analysis.

\section{Measures}

The questionnaire included 4 domains: (A) HH knowledge, (B) HH perceptions, (C) HH attitudes and role models, and (D) participant demographics and hospital characteristics.

The knowledge domain (A) was adapted from the 2009 revision of the World Health Organization (WHO) Hand Hygiene Knowledge Questionnaires for Health-Care Workers, which are composed of questions about the main route of transmission of germs, sources of HAls, the timing of HH to prevent transmission of germs to patients or to other healthcare workers, knowledge about handwashing and alcohol-based hand rubs, knowledge about $\mathrm{HH}$ methods for clinical situations, and practices for increasing the prevalence of $\mathrm{HH}$ [14]. The 25 items included multiple-choice, true/false, and yes/no (coded as right answer $=1$, wrong answer $=0$ ) items, with a total score range of $0-25$ points (Table $S 1$ ).

The perceptions domain (B) was also adapted from the WHO questionnaire to identify perceptions and performance [15]. Three questions (B2, B3, and B4 in Table S2) were excluded from the total score because they reduced the reliability of the questionnaire (Cronbach alpha, 0.729 with all questions; 0.932 after exclusion). Eleven of the 16 items were on a 1- to 7-point scale from 'not effective' to 'very effective', or 'very low' to 'very high', with a total score range of 11-77 points. Question B1 was used to assess self-reported HAI rates. Two other questions (B5 and B11) were analysed separately as indicators of the self-reported $\mathrm{HH}$ performance of non-self and self.

The attitudes and role models domain (C) was adapted from 
a previous study [8]. It was a self-report questionnaire consisting of 8 items on a 1- to 7-point scale from 'not effective' to 'very effective' [8]. The total scores ranged from 8 to 56 . $\mathrm{HH}$ role models were assessed with 7 items on a 1- to 7-point scale from 'do not agree' to 'strongly agree', with a total score range of 7-49 points.

A higher score in each domain indicated greater knowledge, more positive perceptions, more frequent performance, better attitudes, and higher scores for role models, respectively.

\section{Pilot Study}

The WHO-based questions were translated into Korean and a pilot study was conducted from June 20 to 21, 2017, during which the translated items were reviewed by nursing professors and RNs to assess the content validity and to refine a checklist. Pilot study participants were asked to comment on whether the questionnaire items adequately sampled each domain; the questions were accurate, clear, and easy to understand; the instructions were clear and complete; and any of the questions or statements might lead to discord. The suitability of the questionnaire for use was confirmed by the pilot study. Participants' time to complete the questionnaire was recorded and within-domain reliability was calculated.

\section{Participant demographics and hospital characteristics}

Demographic variables included participants' age, sex, religion, marital status, education level, clinical work experience (years), department, and position. Hospital characteristics included the type of hospital, number of beds, HH guidelines, presence of an infection control department (ICD), presence of an infection control nurse (ICN), number of $\mathrm{HH}$ sinks, number of alcohol-based hand rubs, experiences of $\mathrm{HH}$ education within the last year, $\mathrm{HH}$ campaigns, $\mathrm{HH}$ monitoring and feedback, and mass media information. Yes/no answers were coded as 'yes' $=1$, 'no' $=0$.

\section{Data Analysis}

Data were analysed using SPSS version 24.0 (IBM Corp., Armonk, NY, USA), and alpha values $<0.05$ were considered to indicate statistical significance. The Cronbach alpha was calculated to determine reliability.

Descriptive statistics were calculated. Descriptive data for knowledge, perceptions, attitudes, role models, and self-reported $\mathrm{HH}$ performance are presented as mean \pm standard deviation (SD), minimum, maximum, and median. The per- centage of correct answers to each question in the knowledge domain was scaled as high (90\% and over), medium (70-89\%), and low (69\% and below). This scale was established after the proportion of correct answers of each question was analysed (Table S2); the mean and SD were calculated as 70.3 and $30.8 \%$, respectively. Thus, $70 \%$ was assigned as a medium score, and a high score would be recommended to correspond to the mean 1 or $2 \mathrm{SD}$; however in this study, that figure would be over $100 \%$, so $90 \%$ was assigned as the cutoff for a high score.

The data were found not to be distributed normally based on the Kolmogorov-Smirnov test $(p<0.001)$. Non-parametric univariate statistical analyses were conducted using the MannWhitney $\mathrm{U}$ and Kruskal-Wallis tests. Simple linear regression analysis was conducted to confirm the relationship between the self-reported $\mathrm{HH}$ performance of self and that of non-self. Pearson correlation analysis was conducted to identify associations among knowledge, perceptions, attitudes, and self-reported $\mathrm{HH}$ performance of self.

Multivariate analysis with multiple linear regression with stepwise variable selection was conducted using variables that were confirmed to be statistically significant in the univariate analysis and correlation analysis.

\section{Reliability}

The Cronbach alpha values were 0.611 (domain A, knowledge), 0.932 (domain $B$, perceptions), 0.774 (domain $C$, attitudes) and 0.900 (domain C, role models) in this study. These values were $0.381,0.532,0.576$, and 0.932 , respectively, in the pilot study.

\section{Ethics}

The study was approved by the institutional review board of Sunchon National University (104173-201705-HR-013-02, 104173-201709-HR-023-02). Prior to participating, written informed consent was obtained from each participant; participants were also informed that their consent could be withdrawn at any time during the study.

\section{RESULTS}

\section{Descriptive Statistics}

\section{Characteristics of hospitals and participants}

In the 5 hospitals included in this study, there were $319.0 \pm$ 223.5 beds (mean \pm SD) and $441.9 \pm 383.7$ (mean \pm SD) HCWs, 
Table 1. General characteristics of participants $(n=289)$

\begin{tabular}{|c|c|}
\hline Variables & $\mathbf{n}(\%)$ \\
\hline Age (mean $\pm S D, y)$ & $31.2 \pm 7.3$ \\
\hline Clinical work experience (mean $\pm S D, y)$ & $8.9 \pm 7.1$ \\
\hline $\begin{array}{l}\text { Marital status } \\
\text { Unmarried } \\
\text { Married }\end{array}$ & $\begin{array}{l}142(49.1) \\
147(50.8)\end{array}$ \\
\hline $\begin{array}{l}\text { Education level } \\
\text { 3-Year college } \\
\text { Bachelor's } \\
\text { Master's or PhD } \\
\text { Unspecified }\end{array}$ & $\begin{array}{c}136(47.1) \\
128(44.3) \\
19(6.6) \\
3(1.0)\end{array}$ \\
\hline $\begin{array}{l}\text { Department } \\
\text { Internal medicine } \\
\text { Surgery } \\
\text { Obstetrics/pediatrics } \\
\text { Intensive care unit } \\
\text { Emergency } \\
\text { Outpatient } \\
\text { Operating room } \\
\text { Other }\end{array}$ & $\begin{array}{c}41(14.2) \\
63(21.8) \\
75(26.0) \\
28(9.7) \\
9(3.1) \\
19(6.6) \\
15(5.2) \\
39(13.5)\end{array}$ \\
\hline $\begin{array}{l}\text { Position (nurse) } \\
\text { Staff } \\
\text { Charge } \\
\text { Head }\end{array}$ & $\begin{array}{r}230(79.6) \\
34(11.8) \\
25(8.6)\end{array}$ \\
\hline Received $\mathrm{HH}$ education within last year (yes) & $273(94.5)$ \\
\hline Routine use of alcohol-based hand rub (yes) & $265(91.7)$ \\
\hline Monitored others' HH performance (yes) & $213(73.7)$ \\
\hline HH performance was monitored (yes) & $236(81.7)$ \\
\hline HH campaign (yes) & $168(58.1)$ \\
\hline Received information from mass media (yes) & $266(92.0)$ \\
\hline HH guidelines (yes) & $284(98.3)$ \\
\hline Infection control department (yes) & $253(87.5)$ \\
\hline Infection control nurse (yes) & $260(90.0)$ \\
\hline $\begin{array}{l}\text { No. of sinks (/room) } \\
1 \\
2 \\
>2\end{array}$ & $\begin{array}{r}116(40.1) \\
51(17.6) \\
111(38.4)\end{array}$ \\
\hline $\begin{array}{l}\text { No. of alcohol-based hand rub stations } \\
1 / \text { nurse or health care worker } \\
>1 / \text { bed } \\
1 / \text { bed } \\
1 / \text { room }\end{array}$ & $\begin{array}{r}6(2.1) \\
35(12.0) \\
185(64.0) \\
41(14.2)\end{array}$ \\
\hline
\end{tabular}

SD, standard deviation; $\mathrm{HH}$, hand hygiene.
3 had an ICD and 4 had an ICN (1 had a part-time ICN, 3 had full-time ICNs), and 2 were general hospitals.

The demographics and general characteristics of the participants are presented in Table 1.

\section{Knowledge}

Participants' mean \pm SD score of knowledge was 17.6 \pm 2.5 ; the proportion of high and medium levels of correct answers for knowledge was $68.0 \%$ (Table 2).

Some questions showed a low proportion of correct answers, as follows (Table S1): "A3: What is the most frequent source of germs responsible for health care-associated infections?" (40.8\%); "A4-2: Hand rubbing causes skin dryness more than hand washing" (27.7\%); "A7-3: After exposure to the immediate surroundings of a patient" (10.0\%); "A8-4: After exposure to the immediate surroundings of a patient" (11.4\%); "A10-4: Regular use of a hand cream" (0.7\%).

\section{Perceptions and performance}

Participants' mean \pm SD perception score was $69.3 \pm 0.8$ (Table S2). The following questions about perceptions showed low mean \pm SD scores: "B6.3: $\mathrm{HH}$ posters are displayed at points of care as reminders" (6.2 \pm 1.0$)$, "B7: What importance does the head of your department attach to the fact that you perform optimal HH?" (6.2 \pm 1.0$)$, "B8: What importance do your colleagues attach to the fact that you perform optimal $\mathrm{HH}$ ?" (6.2 \pm 1.0$)$, and "B9: What importance do patients attach to the fact that you perform optimal $\mathrm{HH}$ ?" $(6.2 \pm 1.0)$.

The self-reported HAI rate (\%) was identified as $33.2 \pm 27.8$ (mean \pm SD). The self-reported HH performance of non-self (other HCWs) was $86.0 \pm 11.0$ (mean \pm SD). The self-reported $\mathrm{HH}$ performance of self was $88.2 \pm 11.0$ (mean $\pm \mathrm{SD}$ ); this was highest after body fluid exposure/risk $(96.2 \pm 9.6)$ and lowest before touching a patient ( $81.3 \pm 17.6)$.

Table 2. Scores and proportions of correct answers in the knowledge domain

\begin{tabular}{|c|c|c|c|c|c|c|}
\hline Variables & Category (\%) & Mean \pm SD & Min & Max & Median & $\begin{array}{c}\text { Questions, } \\
\text { n (\%) }\end{array}$ \\
\hline Scores of knowledge (range: 0-25) & & $17.6 \pm 2.5$ & 10.0 & 22.0 & 17.5 & \\
\hline Proportion of correct answers for each question in the knowledge domain (\%) & & $70.3 \pm 30.8$ & 0.7 & 99.0 & 85.8 & \\
\hline Category of proportions of correct answers for each question & $\begin{array}{l}\text { High }(\geq 90) \\
\text { Medium }(70-89) \\
\text { Low }(\leq 69)\end{array}$ & & & & & $\begin{array}{r}10(40.0) \\
7(28.0) \\
8(32.0)\end{array}$ \\
\hline
\end{tabular}

SD, standard deviation; Min, minimum; Max, maximum. 


\section{Attitudes and role models}

Participants' mean \pm SD scores in the attitudes and role models of $C$ domains were $50.5 \pm 5.5$ and $46.9 \pm 3.3$ (Table S2). Some questions on attitudes showed extraordinarily low mean $\pm \mathrm{SD}$ scores. In particular, the scores of " $\mathrm{C} 7: \mathrm{HH}$ is convenient." and "C8: $\mathrm{HH}$ is protective" were $5.9 \pm 1.3$, and $5.2 \pm 1.9$, respectively.

Some questions on role models showed low mean \pm SD scores, as follows (Table S2): "CR1: I think that the charge nurse is performing according to the hospital's regulations" and "CR6: I think that my colleague nurses are performing $\mathrm{HH}$ according to the hospital's regulations" both received a score of $6.6 \pm 0.6$.

\section{Univariate Analysis}

The mean knowledge scores were significantly higher among participants who had received $\mathrm{HH}$ education within the past year; those who worked at a hospital with an ICD, ICN, or HH campaign, or where HH performance was monitored; those who worked in general hospitals; and those whose hospitals employed a full-time ICN (compared with those with no ICN or a part-time ICN) (Table 3).

The mean perceptions scores were significantly higher among participants whose $\mathrm{HH}$ performance was monitored; those who monitored their colleagues' $\mathrm{HH}$ performance; those who had experienced HH campaigns; those who were married; those who had higher education levels; and those who had higher positions (Table 3).

The mean scores for self-reported $\mathrm{HH}$ performance of self were significantly higher among $\mathrm{HCWs}$ who had received $\mathrm{HH}$ education within the past year; those whose $\mathrm{HH}$ performance was monitored; those who monitored their colleagues' $\mathrm{HH}$ performance; and those who had higher positions (Table 3).

No independent variables were associated with significant differences in the scores for attitudes or role models in the univariate analyses.

\section{Correlation Analysis}

The correlation analysis among knowledge, perceptions, attitudes, and self-reported HH performance of self identified significant positive correlations among all categories except knowledge (Table 4).

\section{Simple Linear Regression}

The model for the self-reported $\mathrm{HH}$ performance rates of self and non-self was follows. The HH performance rate of
Table 3. Results of univariate analysis of knowledge, perceptions, and performance

\begin{tabular}{|c|c|c|c|c|c|}
\hline Domains & Variables & & $\begin{array}{c}\text { Mean } \pm \\
\text { SD }\end{array}$ & $\mathbf{n}$ & $p$-value \\
\hline \multirow[t]{15}{*}{ Knowledge } & \multirow{2}{*}{$\begin{array}{l}\text { Receiving } \\
\text { education } \\
\text { within the } \\
\text { past year }\end{array}$} & Yes & $17.7 \pm 2.4$ & 273 & 0.04 \\
\hline & & No & $16.3 \pm 2.5$ & 16 & \\
\hline & \multirow{2}{*}{$\begin{array}{l}\text { Infection control } \\
\text { department }\end{array}$} & Yes & $17.9 \pm 2.4$ & 223 & $<0.001$ \\
\hline & & No & $16.5 \pm 2.2$ & 66 & \\
\hline & \multirow{2}{*}{$\begin{array}{l}\text { Infection control } \\
\text { nurse }\end{array}$} & Yes & $17.7 \pm 2.3$ & 268 & 0.003 \\
\hline & & No & $16.1 \pm 2.7$ & 21 & \\
\hline & \multirow[t]{2}{*}{ HH campaign } & Yes & $17.8 \pm 2.6$ & 121 & 0.03 \\
\hline & & No & $17.3 \pm 2.1$ & 25 & \\
\hline & \multirow{2}{*}{$\begin{array}{r}\text { HH performance } \\
\text { was monitored }\end{array}$} & Yes & $17.7 \pm 2.4$ & 236 & 0.04 \\
\hline & & No & $16.9 \pm 2.4$ & 50 & \\
\hline & \multirow[t]{2}{*}{ Type of hospital } & $\begin{array}{l}\text { General } \\
\text { hospital }\end{array}$ & $18.0 \pm 2.3$ & 173 & $<0.001$ \\
\hline & & Hospital & $16.9 \pm 2.4$ & 116 & \\
\hline & \multirow{3}{*}{$\begin{array}{l}\text { Type of } \\
\text { infection } \\
\text { control nurse }\end{array}$} & Full-time & $17.9 \pm 2.4$ & 45 & $<0.001^{2}$ \\
\hline & & Part-time & $16.8 \pm 1.9$ & 45 & \\
\hline & & None & $16.1 \pm 2.7$ & 21 & \\
\hline \multirow[t]{15}{*}{ Perceptions } & \multirow{2}{*}{$\begin{array}{l}\text { HH perfor- } \\
\text { mance was } \\
\text { monitored }\end{array}$} & Yes & $70.0 \pm 7.4$ & 236 & 0.004 \\
\hline & & No & $65.6 \pm 9.5$ & 50 & \\
\hline & \multirow{2}{*}{$\begin{array}{c}\text { Monitored col- } \\
\text { leagues' HH } \\
\text { performance }\end{array}$} & Yes & $70.0 \pm 7.8$ & 213 & 0.003 \\
\hline & & No & $67.2 \pm 8.1$ & 75 & \\
\hline & \multirow[t]{2}{*}{ HH campaign } & Yes & $70.6 \pm 7.3$ & 168 & $<0.001$ \\
\hline & & No & $67.4 \pm 8.5$ & 121 & \\
\hline & \multirow[t]{2}{*}{ Marital status } & Married & $70.4 \pm 7.4$ & 147 & 0.02 \\
\hline & & Unmarried & $68.1 \pm 8.4$ & 142 & \\
\hline & \multirow[t]{4}{*}{ Education level } & $\begin{array}{l}\text { 3-Year } \\
\text { college }\end{array}$ & $68.6 \pm 8.7$ & 136 & $0.01^{2}$ \\
\hline & & Bachelor's & $69.3 \pm 7.3$ & 128 & \\
\hline & & $\begin{array}{l}\text { Master's or } \\
\text { PhD }\end{array}$ & $74.6 \pm 3.4$ & 19 & \\
\hline & & Unspecified & $72.3 \pm 8.1$ & 3 & \\
\hline & \multirow[t]{3}{*}{ Position (nurse) } & Staff & $68.7 \pm 8.2$ & 230 & $0.001^{2}$ \\
\hline & & Charge & $70.0 \pm 7.1$ & 34 & \\
\hline & & Head & $74.2 \pm 4.6$ & 25 & \\
\hline \multirow{9}{*}{$\begin{array}{l}\text { Self-reported } \\
\text { HH } \\
\text { performance } \\
\text { of self }\end{array}$} & \multirow{2}{*}{$\begin{array}{l}\text { Received edu- } \\
\text { cation within } \\
\text { the past year }\end{array}$} & Yes & $86.5 \pm 10.7$ & 241 & $<0.001$ \\
\hline & & No & $76.4 \pm 12.2$ & 14 & \\
\hline & \multirow{2}{*}{$\begin{array}{r}\text { HH performance } \\
\text { was monitored }\end{array}$} & Yes & $86.7 \pm 10.9$ & 209 & 0.01 \\
\hline & & No & $83.0 \pm 11.0$ & 44 & \\
\hline & \multirow{2}{*}{$\begin{array}{l}\text { Monitored col- } \\
\text { leagues' HH } \\
\text { performance }\end{array}$} & Yes & $86.8 \pm 11.1$ & 192 & 0.005 \\
\hline & & No & $83.4 \pm 10.3$ & 63 & \\
\hline & \multirow[t]{3}{*}{ Position (nurse) } & Staff & $87.3 \pm 11.6$ & 230 & $0.04^{2}$ \\
\hline & & Charge & $91.7 \pm 7.0$ & 34 & \\
\hline & & Head & $91.7 \pm 8.4$ & 25 & \\
\hline
\end{tabular}

SD, standard deviation; $H H$, hand hygiene.

${ }^{1}$ Non-parametric univariate analysis (Mann-Whitney).

${ }^{2}$ Kruskal-Wallis test . 
Table 4. Results of correlation analysis of knowledge, perceptions, attitudes, role models, and performance

\begin{tabular}{lcccc}
\hline & Knowledge & Perceptions & Attitudes & $\begin{array}{c}\text { Role models } \\
\text { Self-reported HH } \\
\text { performance of self }\end{array}$ \\
\hline Knowledge & 1.000 & & & \\
Perceptions & -0.036 & 1.000 & 1.000 & 1.000 \\
Attitudes & -0.075 & $0.422^{* * *}$ & $0.368^{* * *}$ & $0.414^{* * *}$ \\
Role models & 0.094 & $0.349^{* * *}$ & $0.281^{* * *}$ & 1.000 \\
Self-reported HH performance of self & 0.034 & $0.303^{* * *}$ & \\
\hline
\end{tabular}

$\mathrm{HH}$, hand hygiene.

${ }^{* * *} p<0.001$ : two tailed by Pearson's correlation analysis.

Table 5. Results of simple linear regression analysis and multiple linear regression analysis

\begin{tabular}{|c|c|c|c|c|c|c|c|c|}
\hline Dependent variables & Independent variables & $\begin{array}{c}\beta \\
\text { (standardized) }\end{array}$ & $t$-value & $p$-value & $95 \% \mathrm{CI}$ & Partial R & VIF & $\begin{array}{c}\text { Adjusted R² } \\
\text { (p-value) }\end{array}$ \\
\hline $\begin{array}{l}\text { Self-reported HH } \\
\text { performance of non-self }{ }^{1}\end{array}$ & $\begin{array}{l}\text { Intercept } \\
\text { Self-reported } \mathrm{HH} \\
\text { performance of self }\end{array}$ & $\begin{array}{c}36.678 \\
0.555(0.532)\end{array}$ & $\begin{array}{r}7.391 \\
10.000\end{array}$ & $\begin{array}{l}<0.001 \\
<0.001\end{array}$ & $\begin{array}{c}26.904,46.452 \\
0.446,0.664\end{array}$ & 0.532 & & $0.280(<0.001)$ \\
\hline Knowledge & $\begin{array}{l}\text { Intercept } \\
\text { Receiving education } \\
\text { within the past year }{ }^{2} \\
\text { Infection control department }{ }^{2} \\
\text { Infection control nurse }^{2} \\
\text { Type of hospital }{ }^{3}\end{array}$ & $\begin{array}{c}16.956 \\
0.486(0.046) \\
0.682(0.120) \\
0.451(0.049) \\
-0.558(-0.114)\end{array}$ & $\begin{array}{r}17.082 \\
0.693 \\
\\
1.424 \\
0.656 \\
-1.488\end{array}$ & $\begin{array}{c}<0.001 \\
0.49 \\
0.16 \\
0.51 \\
0.14\end{array}$ & $\begin{array}{l}15.002,18.910 \\
-0.895,1.867 \\
-0.261,1.625 \\
-0.901,1.802 \\
-1.296,0.180\end{array}$ & $\begin{array}{r}0.041 \\
0.084 \\
0.039 \\
-0.088\end{array}$ & $\begin{array}{l}1.368 \\
2.150 \\
1.689 \\
1.795\end{array}$ & $0.055(<0.001)$ \\
\hline Perception & $\begin{array}{l}\text { Intercept } \\
\text { HH performance } \\
\text { was monitored }{ }^{2} \\
\text { Monitored colleagues' HH }^{\prime} \text { performance }^{2} \\
\text { HH campaign }{ }^{2} \\
\text { Marital status } \\
\text { Education level } \\
\text { Position }\end{array}$ & $\begin{array}{c}61.408 \\
2.566(0.123) \\
1.054(0.058) \\
1.611(0.100) \\
0.850(0.054) \\
0.871(0.072) \\
0.978(0.106)\end{array}$ & $\begin{array}{r}31.667 \\
1.791 \\
\\
0.835 \\
\\
1.522 \\
0.856 \\
1.168 \\
1.605\end{array}$ & $\begin{array}{c}<0.001 \\
0.07 \\
0.40\end{array}$ & $\begin{array}{l}57.591,65.226 \\
-0.255,5.387 \\
-1.431,3.540 \\
-0.473,3.694 \\
-1.103,2.803 \\
-0.597,2.339 \\
-0.221,2.178\end{array}$ & $\begin{array}{l}0.091 \\
0.051 \\
0.070 \\
0.096\end{array}$ & $\begin{array}{l}1.449 \\
1.467 \\
1.321 \\
1.194 \\
1.175 \\
1.339\end{array}$ & $0.078(<0.001)$ \\
\hline $\begin{array}{l}\text { Self reported HH } \\
\text { performance of self }\end{array}$ & $\begin{array}{l}\text { Intercept } \\
\text { Perceptions } \\
\text { Attitudes } \\
\text { Role models }\end{array}$ & $\begin{array}{c}18.302 \\
0.247(0.178) \\
0.232(0.116) \\
0.875(0.261)\end{array}$ & $\begin{array}{l}2.124 \\
2.857 \\
1.819 \\
4.233\end{array}$ & $\begin{array}{l}0.03 \\
0.005 \\
0.07 \\
<0.001\end{array}$ & $\begin{array}{c}1.345,35.260 \\
0.077,0.417 \\
-0.019,0.483 \\
0.468,1.282\end{array}$ & $\begin{array}{l}0.167 \\
0.107 \\
0.243\end{array}$ & $\begin{array}{l}1.384 \\
1.437 \\
1.356\end{array}$ & $0.191(<0.001)$ \\
\hline
\end{tabular}

$\mathrm{HH}$, hand hygiene; $\mathrm{Cl}$, confidence interval; VIF, variance inflation factor.

${ }^{1}$ Simple linear regression analysis.

${ }^{2}$ Binary predictors (yes, $1 ;$ no, 0).

${ }^{3}$ General hospital, 1; hospital, 2.

non-self was calculated as $Y_{1}=36.678+0.555 X_{1}$ (HH performance rate of self), and a significant linear relationship was found (adjusted $R^{2}=0.280, p<0.001$ ) (Table 5).

\section{Multiple Linear Analyses}

The regression model for knowledge was calculated as $Y_{2}=16.956+0.486 X_{21}$ (receiving education within the past year) $+0.682 X_{22}$ (ICD) $+0.451 X_{23}$ (ICN) $-0.558 X_{24}$ (type of hospital). The coefficient of each predictor was not statistically significant, but the model as a whole did show statistical significance (adjusted $\mathrm{R}^{2}=0.055, p<0.001$ ) (Table 5).

The regression model for perceptions was calculated as
$Y_{3}=61.408+2.566 X_{31}$ (HH performance was monitored)+ $1.054 X_{32}$ (monitoring colleagues' HH performance) $+1.611 X_{33}$ (HH campaign) $+0.850 X_{34}$ (marital status) $+0.871 X_{35}$ (education level) $+0.978 X_{36}$ (position). The coefficients were not statistically significant, but the model as a whole did show statistical significance (adjusted $R^{2}=0.078, p<0.001$ ) (Table 5). The regression model for self-reported $\mathrm{HH}$ performance of self was not calculated by multiple linear regression using the variables found to be significant in the univariate analysis.

The regression model for performance was calculated as $Y_{4}=18.302+0.247 X_{41}$ (perceptions) $+0.232 X_{42}$ (attitudes) + $0.875 X_{42}$ (role model); the coefficients were statistically signifi- 
cant except attitude, and this model showed statistical significance (adjusted $\mathrm{R}^{2}=0.191, p<0.001$ ) (Table 5).

\section{DISCUSSION}

In terms of infection control infrastructure [16], ICDs and ICNs were not fully allocated across the hospitals analysed in this study. The values for numbers of sinks and the placement of alcohol-based hand rub stations in this study were no worse than has been reported in previous studies (in 2014) of large Korean hospitals [17]. However, as resources for $\mathrm{HH}$, the placement of sinks in every room and alcohol-based hand rub stations by every bed, as well as supplying alcohol-based hand rub to every HCW should be improved continuously. In terms of $\mathrm{HH}$ activities, most participants (94.5\%) had received $\mathrm{HH}$ education; however, the scores for other activities such as $\mathrm{HH}$ campaign experience and $\mathrm{HH}$ monitoring activities were low. These issues can be easily resolved with ICD and ICN placement $[16,18]$. Such improvements should be made continuously until the Korean health care quality standards are satisfied [19].

The mean score of knowledge among our participants (17.6 \pm 2.5$)$ was higher than was reported in previous studies $(8.1 \pm 1.4$ [8], $14.2 \pm 2.0$ [10], and $14.2 \pm 2.6$ [20]) conducted by the same method (WHO questionnaire). However, the proportion of medium and high levels of correct answers was $68.0 \%$. Moreover, serious weaknesses in knowledge were found in response to the following questions: "What is the most frequent source of germs responsible for health care-associated infections?", "Hand rubbing causes skin dryness more than hand washing", "A7-3: After exposure to the immediate surroundings of a patient", "A8-4: After exposure to the immediate surroundings of a patient", and "Regular use of a hand cream". Therefore, $\mathrm{HH}$ education programs should be promptly reviewed, and systemic and advanced HH education and training programs must be developed and implemented to enhance HH knowledge broadly, not just focusing on these specific knowledge questions.

The perceptions in this study $(69.3 \pm 0.8$; total score, 77$)$ were somewhat higher than observed in a previous study (75.2 \pm 11.8; total score, 96) [10]. However, some perceptions-related items that received low scores should be improved, because perceptions have been shown to be significant predictors of nurses' $\mathrm{HH}$ intentions and adherence [21], and an important predictor of $\mathrm{HH}$ performance $[13,22]$.
Self-reported $\mathrm{HH}$ performance of self was highest after body fluid exposure/risk and lowest before touching a patient. This finding corresponds to those of previous observational studies $[9,23]$ and is consistent with a previous self-reported performance study [24]. Interestingly, the relationship between the $\mathrm{HH}$ performance of self and that of non-self was positive and linear. This finding is also consistent with a previous report [25]. Participants evaluated the HH performance of non-self at 0.555 times the $\mathrm{HH}$ performance of self.

Attitudes about $\mathrm{HH}$ were relatively poor in responses to both "HH is convenient" and "HH is protective". These findings may represent barriers to maintaining good $\mathrm{HH}$, and also demonstrate the need for strategies to promote the perceived convenience and protectiveness of $\mathrm{HH}$ [1].

In the role model domain, "It is important for my colleagues to perform HH according to the hospital's regulations" showed high endorsement, and nursing colleagues were identified as the most important $\mathrm{HH}$ role models. These results are consistent with previous studies [11-13,21,26]. Moreover, the perception of being a role model for one's colleagues can be used to improve HH compliance [13,25].

According to the multiple linear regression analysis, receiving education within the past year (yes), having an ICD (yes), and having an ICN (yes) positively affected knowledge, while type of hospitals negatively affected knowledge. HH performance being monitored (yes), monitoring colleagues' $\mathrm{HH}$ performance (yes), and the presence of an $\mathrm{HH}$ campaign (yes) positively affected perceptions. Therefore, these findings can be used to improve knowledge and perceptions.

As this study was not an observational study of $\mathrm{HH}$ performance, this study has some limitations in terms of the self-reporting of $\mathrm{HH}$ performance. The regression model of self-reported $\mathrm{HH}$ performance of self showed increases with 0.247 (perceptions) +0.232 (attitudes) +0.875 (role models). Knowledge was excluded from this model. Consistently with previous studies $[13,21,22,25]$, our participants' self-reported HH performance rate of self was positively correlated with their scores for perceptions, attitudes, and role models. An explanation for this is that general perceptions of $H H[13,21,22]$ and the perception of being a role model for one's colleagues $[13,25]$ are very important for improving $\mathrm{HH}$ compliance among HCWs [13]. As such, these findings could be used in future $\mathrm{HH}$ promotion strategies for nurses.

In this study, the HH knowledge, perceptions, attitudes, and role models of RNs in community-based hospitals in a small- 
to-medium urban area were characterized. The presence of some items with relatively low scores revealed some room for improvements in knowledge. Receiving education within the past year, having an ICD, and having an ICN were found to be related to knowledge. In addition, $\mathrm{HH}$ campaigns and monitoring were associated with perceptions. The self-reported $\mathrm{HH}$ performance rate of self was associated with perceptions, attitudes, and role models.

\section{ACKNOWLEDGEMENTS}

This research was supported by Sunchon National University funds (2017).

\section{CONFLICT OF INTEREST}

The author has no conflicts of interest associated with the material presented in this paper.

\section{SUPPLEMENTAL MATERIALS}

Supplementary Material 1: Table S1 is available at https:// www.jpmph.org/.

Supplementary Material 2: Table S2 is available at https:// www.jpmph.org/

\section{ORCID}

Hyang Soon Oh http://orcid.org/0000-0002-5709-2861

\section{REFERENCES}

1. World Health Organization. WHO guidelines on hand hygiene in health care: first global patient safety challenge clean care is safer care; 2009 [cited 2017 Dec 22]. Available from: http:// apps.who.int/iris/bitstream/10665/44102/1/9789241597906 _eng.pdf.

2. Office of Disease Prevention and Health Promotion. Overview: health care-associated infections [cited 2017 Dec 2]. Available from: https://health.gov/hcq/prevent-hai.asp.

3. Pittet D, Allegranzi B, Sax H, Dharan S, Pessoa-Silva CL, Donaldson $\mathrm{L}$, et al. Evidence-based model for hand transmission during patient care and the role of improved practices. Lancet Infect Dis 2006;6(10):641-652.

4. Kirk J, Kendall A, Marx JF, Pincock T, Young E, Hughes JM, et al.
Point of care hand hygiene-where's the rub? A survey of US and Canadian health care workers' knowledge, attitudes, and practices. Am J Infect Control 2016;44(10):1095-1101.

5. Ki M. 2015 MERS outbreak in Korea: hospital-to-hospital transmission. Epidemiol Health 2015;37:e2015033.

6. Kim KH, Tandi TE, Choi JW, Moon JM, Kim MS. Middle East respiratory syndrome coronavirus (MERS-CoV) outbreak in South Korea, 2015: epidemiology, characteristics and public health implications. J Hosp Infect 2017;95(2):207-213.

7. Oh HS, Chung HW, Kim JS, Cho SI. National survey of the status of infection surveillance and control programs in acute care hospitals with more than 300 beds in the Republic of Korea. Am J Infect Control 2006;34(4):223-233.

8. Jeong SY, Kim O. Knowledge and beliefs about hand hygiene among hospital nurses. Korean J Occup Health Nurs 2013; 22(3):198-207 (Korean).

9. Oh HS. Hand hygiene compliance of healthcare workers in a children's hospital. Pediatr Infect Vaccine 2015;22(3):186-193 (Korean).

10. Kim EK, Joo MK, Baik SY, Hong SK. P161: knowledge and perception toward hand hygiene among health-care workers in teaching hospital, Korea. Antimicrob Resist Infect Control 2013; 2(Suppl 1):P161.

11. Burnett E. Perceptions, attitudes, and behavior towards patient hand hygiene. Am J Infect Control 2009;37(8):638-642.

12. White KM, Jimmieson NL, Graves N, Barnett A, Cockshaw W, Gee $\mathrm{P}$, et al. Key beliefs of hospital nurses' hand-hygiene behaviour: protecting your peers and needing effective reminders. Health Promot J Austr 2015;26(1):74-78.

13. Lee SS, Park SJ, Chung MJ, Lee JH, Kang HJ, Lee JA, et al. Improved hand hygiene compliance is associated with the change of perception toward hand hygiene among medical personnel. Infect Chemother 2014;46(3):165-171.

14. World Health Organization. Hand hygiene knowledge questionnaire for health-care workers; 2009 [cited 2017 Dec 22]. Available from: http://www.who.int/entity/gpsc/5may/ Hand_Hygiene_Knowledge_Questionnaire.doc?ua $=1$.

15. World Health Organization. Perception survey for health-care workers; 2009 [cited 2017 Dec 22]. Available from: http://www. who.int/entity/gpsc/5may/Perception_Survey_for_Health_ care_Workers.doc?ua $=1$.

16. Hughes JM. Study on the efficacy of nosocomial infection control (SENIC Project): results and implications for the future. Chemotherapy 1988;34(6):553-561.

17. Jeong SY, Kim OS, Lee JY. The status of healthcare-associated 
infection control among healthcare facilities in Korea. J Digit Converg 2014;12(5):353-366 (Korean).

18. Oh HS, Cheong HW, Yi SE, Kim H, Choe KW, Cho SI. Development and application of evaluation indices for hospital infection surveillance and control programs in the Republic of Korea. Infect Control Hosp Epidemiol 2007;28(4):435-445.

19. Korea Institute for Healthcare Accreditation. Reference material [cited 2017 Dec 22]. Available from: https://www.koiha. or.kr/member/kr/board/establish/establish_BoardList.do (Korean).

20. Nabavi M, Alavi-Moghaddam M, Gachkar L, Moeinian M. Knowledge, attitudes, and practices study on hand hygiene among Imam Hossein Hospital's residents in 2013. Iran Red Crescent Med J 2015;17(10):e19606.

21. White KM, Starfelt LC, Jimmieson NL, Campbell M, Graves N, Barnett AG, et al. Understanding the determinants of Australian hospital nurses' hand hygiene decisions following the implementation of a national hand hygiene initiative. Health Educ Res 2015;30(6):959-970.

22. Tai JW, Mok ES, Ching PT, Seto WH, Pittet D. Nurses and physi- cians' perceptions of the importance and impact of healthcare-associated infections and hand hygiene: a multi-center exploratory study in Hong Kong. Infection 2009;37(4):320333.

23. Oh HS. Analysis of hand hygiene practices of health care personnels. J Korea Acad Ind Coop Soc 2015;16(9):6160-6168 (Korean).

24. Diwan V, Gustafsson C, Rosales Klintz S, Joshi SC, Joshi R, Sharma $\mathrm{M}$, et al. Understanding Healthcare workers self-reported practices, knowledge and attitude about hand hygiene in a medical setting in rural India. PLoS One 2016;11(10):e0163347.

25. Alp E, Ozturk A, Guven M, Celik I, Doganay M, Voss A. Importance of structured training programs and good role models in hand hygiene in developing countries. J Infect Public Health 2011;4(2):80-90.

26. Asadollahi M, Arshadi Bostanabad M, Jebraili M, Mahallei M, Seyyed Rasooli A, Abdolalipour M. Nurses' knowledge regarding hand hygiene and its individual and organizational predictors. J Caring Sci 2015;4(1):45-53. 